\title{
MOVILIZACIÓN Y MODERNIDAD EN EL MEDIO ORIENTE
}

\author{
CAMILA PASTOR DE MARIA Y CAMPOS \\ Centro de Investigación y Docencia Económicas
}

Para comprender los procesos que han conformado la modernidad del Medio Oriente es necesario echar una mirada panorámica sobre ellos a fin de captar la lógica de las continuas movilizaciones a lo largo y ancho del mundo árabe el último año y medio, lo que los medios de comunicación internacionales han llamado Primavera árabe, mientras los manifestantes cantan la revolución. Empezaré con una síntesis de las grandes transformaciones puestas en marcha en el siglo XIX, cuando el Mediterráneo oriental emergió como actor de la nueva economía industrial global. Ese periodo de modernización defensiva del Imperio otomano y sus instituciones es crucial para entender la emergencia de nuevos agentes sociales en la región y las transformaciones sociales que persiguieron y precipitaron.

Exploraré diversos movimientos sociales que participaron en los debates sobre el cambio social hacia principios del siglo xx, proponiendo o subvirtiendo reformas del Estado y el orden público durante las últimas décadas del Imperio otomano y el periodo del mandato. Ese periodo se caracterizó por encarnizados debates y la emergencia de nuevas actividades y espacios públicos que permitieron la movilización de agentes sociales ya constituidos y de otros nuevos. El proceso de descolonización de mediados de siglo y la ola de revoluciones que trajo consigo llevaron al poder a sectores históricamente marginados en gran parte de la región, quienes terminaron institucionalizando sus propias visiones del bien común.

Este artículo fue recibido por la dirección de la revista el 7 de marzo de 2013 y aceptado para su publicación el 6 de junio de 2013. 
Al final presento una visión crítica de las formas que la movilización ha tomado en la región en las últimas tres décadas. Analizo el panorama social y las dinámicas de movilización que han producido las revueltas y revoluciones que hoy se desarrollan y discuto sucintamente la representación de la participación de la mujer en las luchas actuales por los medios de comunicación internacionales. El texto busca poner de manifiesto la diversidad de ideologías y prácticas de múltiples agentes sociales y la reestructuración de poblaciones, territorios y experiencia cotidiana de acuerdo con las transformaciones impuestas, reinventadas y diseminadas, que configuran nuevas redes de poder y desigualdad en el transcurso del siglo xx.

\section{Orientalismo, islam y Medio Oriente moderno}

La contextualización de las movilizaciones actuales en las metamorfosis sociales de los últimos 200 años evidencia la limitación del "islam" como factor explicativo, el cual sólo es válido para una visión orientalista que se rehúsa a reconocer las transformaciones producidas por la participación de la región en la creación de una modernidad global institucional, productiva e ideológica. Es posible entonces hacer a un lado los sesgos orientalistas que influyen en mucha de la producción académica y popular que desafortunadamente informa el debate público sobre las revueltas actuales, como lo discutiré en la parte final del trabajo.

El punto de partida para entender el Medio Oriente moderno es la gradual inversión de fuerzas entre el Imperio otomano y la Europa industrial desde fines del siglo XvIII hasta el presente. ${ }^{1} \mathrm{Al}$ enfrentar la expansión de nuevos imperios globales, el sublime porte-Estambul-y los líderes políticos de los territorios desmembrados del control otomano en el siglo XIX realizaron diversas reformas estatales orientadas a remediar la creciente desigualdad resultante de la expansión económica, militar y territorial de los Estados imperiales europeos durante 
ese periodo. ${ }^{2}$ La reforma estaba presente en todos los aspectos de la vida social, redefiniendo los vínculos jurídicos del Estado imperial centralizador con sus súbditos a través, por ejemplo, del Gulhane Sherif, pero también trasformando el tejido social mediante la creación de nuevas instituciones militares y educativas.

En el mismo periodo, grandes áreas del Mediterráneo oriental fueron incorporadas al mercado global, principalmente como abastecedoras de materias primas para las nuevas industrias textiles centradas en Gran Bretaña y Francia; la provincia de Egipto como productora masiva de algodón, Monte Líbano y Alejandreta como regiones productoras de seda y muchas áreas de Siria como productoras de tabaco. Donde hay industria hay trabajadores, y a medida que esas zonas atrajeron trabajadores migrantes otomanos y transmediterráneos en busca de salarios industriales, también atrajeron organizadores radicales de la clase obrera global. La primera ola de huelgas obreras ocurrió a fines del siglo XIX en ciudades portuarias otomanas como Salónica, Izmir, Alejandría, Beirut, Túnez e incluso Estambul, capital del imperio. ${ }^{3}$

La nueva riqueza de la producción de algodón y seda, junto con las leyes que privatizaron la propiedad de la tierra a mediados de siglo, provocaron una redistribución de recursos con configuraciones regionales particulares. Las tierras y la industria algodonera de Egipto fueron acumuladas por la dinastía de Mohamed Alí y sus redes clientelares y familiares, con enormes consecuencias durante la crisis global de producción de algodón provocada por la guerra civil de Estados Unidos. En Monte Líbano y Alejandreta, en cambio, fueron las poblaciones campesinas las que capitalizaron la "protección" histórica de los Estados europeos sobre la base de una cristiandad común, a fin de cultivar vínculos comerciales con la industria francesa de la seda y así prosperar. ${ }^{4}$

${ }^{2}$ William L. Cleveland, A History of Modern Middle East, Boulder, Westview Press, 1994.

${ }^{3}$ Ilham Khuri-Makdisi, The Eastern Mediterranean and the Making of Global Radicalism, 1860-1914, Berkeley, University of California Press, 2010.

${ }^{4}$ A. F. Khater, Inventing Home: Emigration, Gender, and the Middle Class in Lebanon, 1870-1920, Berkeley, University of California Press, 2001. 


\section{Modernidad otomana: 1830-1919}

Las transformaciones políticas y económicas crearon nuevos agentes sociales y nuevas ideologías aglutinados en viejos y nuevos espacios urbanos que experimentaban dramáticas expansiones y renovaciones. La explosión demográfica contribuyó a la consolidación de Estambul, Beirut, Alejandría, El Cairo y Damasco como centros de debate público entre las antiguas élites de notables y las nuevas clases comerciales y profesionales: abogados, militares, periodistas, médicos. Los grandes movimientos sociales que han caracterizado a la región en los últimos dos siglos nacieron en ese contexto de transformación: movimientos migratorios, obreros, nacionalistas, sectarios, antiimperialistas y de mujeres. ${ }^{5}$

Tres procesos son particularmente importantes. Primero, la circulación de personas en circuitos crecientemente expansivos; esto es, las grandes migraciones que alimentaron el crecimiento urbano y una nueva ola de cosmopolitismo por la circulación de poblaciones militares, misionales y obreras dentro del imperio y más allá de sus menguantes fronteras. ${ }^{6}$ Segundo, como

${ }^{5}$ Leila Ahmed, Women and Gender in Islam: Historical Roots of a Modern Debate, New Haven, Yale University Press, 1992; J. Beinin, Workers and Peasants in the Modern Middle East, Cambridge-Nueva York, Cambridge University Press, 2001; J. Beinin y Z. Lockman, Workers on the Nile: Nationalism, Communism, Islam, and the Egyptian Working Class, 1882-1954, Princeton, Princeton University Press, 1987; A. Bourgey, Migrations et changements sociaux dans l'Orient arabe, Beirut, CERMOC, 1985; L. T. Fawaz, Merchants and Migrants in Nineteenth-century Beirut, Cambridge, Harvard University Press, 1983; S. M. A. Gualtieri, Between Arab and White: Race and Ethnicity in the Early Syrian American Diaspora, Berkeley, University of California Press, 2009; James L. Gelvin, The Israel-Palestine Conflict: One Hundred Years of War, Cambridge, Cambridge University Press, 2005; Z. Lockman, Workers and Working Classes in the Middle East: Struggles, Histories, Historiographies, Albany, State University of New York Press, 1994; Z. Lockman, Comrades and Enemies: Arab and Jewish Workers in Palestine, 1906-1948, Berkeley, University of California Press, 1996; U. S. Makdisi, The Culture of Sectarianism: Community, History, and Violence in Nineteenth-century Ottoman Lebanon, Berkeley, University of California Press, 2000; Michael Provence, The Great Syrian Revolt and the Rise of Arab Nationalism, Austin, University of Texas Press, 2005; Elizabeth Thompson, Colonial Citizens: Republican Rights, Paternal Privilege, and Gender in French Syria and Lebanon, Nueva York, Columbia University Press, 2000.

${ }^{6}$ U. S. Makdisi, Artillery of Heaven: American Missionaries and the Failed Conversion of the Middle East, Ithaca, Cornell University Press, 2008; Gualteri, Between Arab and White, op. cit.; Khater, Inventing Home, op. cit.; Khuri-Makdisi, The Eastern Mediterranean..., op. cit.; Camila Pastor de Maria y Campos, "The Mashreq in Mexi- 
consecuencia de la participación de la región en la modernidad, la emergencia de sectores sociales dinámicos excluidos de las bases de riqueza y poder constituidas por las redes clientelares de los mediadores tradicionales entre un Estado imperial descentralizado y las poblaciones locales. ${ }^{7}$ Tercero, el desarrollo de nuevos instrumentos y espacios de debate público entre las élites tradicionales, las élites modernas y sectores populares que ocasionalmente facilitaban interacciones y complicidades entre ellas; instrumentos y espacios como la prensa, el teatro popular y una diversidad de asociaciones que ofrecían oportunidades de interacción y generaron discursos y prácticas: sociedades mutualistas y de bienestar, sociedades científicas, clubes de lectura, logias masónicas, etcétera. ${ }^{8}$

\section{Movimientos de reforma: campesinos, radicales, nacionalistas, clérigos y la cuestión de la mujer}

Esta modernidad otomana de muchas caras entrañó la intervención de varios proyectos civilizatorios en las provincias árabes del imperio. Primero, la misión civilizadora otomana que buscó, como Zeynep Celik ${ }^{9}$ ha notado, rehacer los espacios sociales y urbanos Mashreq sobre el modelo de un Estambul crecientemente turco. Al mismo tiempo, la creciente presencia misional y comercial de agentes franceses, británicos y estadounidenses facilitó transformaciones locales que contribuirían a sostener las redes clientelares que cada Estado imperial cultivaba

co. Patronage, Property and Class in the Postcolonial Global", tesis de doctorado, Universidad de California, Los Ángeles, 2009.

${ }^{7}$ R. Khalidi, The Origins of Arab Nationalism, Nueva York, Columbia University Press, 1991; Khater, Inventing Home, op. cit.; P. S. Khoury, Urban Notables and Arab Nationalism: The Politics of Damascus, 1860-1920, Cambridge [Cambridgeshire]Nueva York, Cambridge University Press, 1983; James L. Gelvin, Divided Loyalties: Nationalism and Mass Politics in Syria at the Close of Empire, Berkeley, University of California Press, 1998.

${ }^{8}$ Beth Baron, The Women's Awakening in Egypt: Culture, Society, and the Press, New Haven, Yale University Press, 1994; Khuri-Makdisi, The Eastern Mediterranean..., op. cit.; Camila Pastor de Maria y Campos, "Palestina como espectáculo en la prensa del mahjar mexicano”, en Ranaan Rein (ed.), Más allá del Medio Oriente. Las diásporas judía y árabe en América Latina, Granada, Universidad de Granada, 2012.

${ }^{9}$ Zeynep Celik, Empire, Architecture, and the City: French-Ottoman Encounters, 1830-1914, Seattle, University of Washington Press, 2008. 
con las poblaciones locales, definidas como "minorías" a través de una lente sectaria.

A medida que los modernos discursos otomanos, que proclamaban la igualdad de los súbditos imperiales ante el imperio, fueron siendo apropiados por poblaciones campesinas crecientemente ricas y educadas por misioneros que colaboraban estrechamente con imperios rivales, las revueltas campesinas comenzaron a germinar. ${ }^{10} \mathrm{La}$ insurgencia campesina rápidamente trazó los contornos de la imaginación orientalista, que la animó por cuenta propia. Como Ilham Khoury-Makdissi ${ }^{11}$ ha notado, las nuevas industrias - la producción de materias primas para la industria textil, pero también las industrias de transporte como el ferrocarril e instalaciones portuarias-generaron una población obrera que desarrolló afinidades ideológicas con los movimientos obreros internacionales emergentes en aquel momento radical global.

La extensión de la educación misional y estatal, especialmente el establecimiento de instituciones de educación superior - militares, misionales y seculares-, generaron una clase media confesionalmente diversa, la que - como Khalidi, Gelvin, Watenpaugh y Provence ${ }^{12}$ han subrayado- produjo los ideólogos de los proliferantes movimientos nacionalistas: turcos, árabes, griegos, armenios, etcétera. La reestructuración de la educación y de la impartición de justicia, según modelos seculares globales, desplazó a las élites académicas musulmanas tradicionales, que perdieron gran parte de las bases materiales y sociales de su autoridad. No sorprende entonces la emergencia de discursos y movimientos reformistas entre musulmanes educados.

Entre los movimientos que abarcan y atraviesan las últimas décadas del siglo xIx y la primera mitad del siglo xx, los nacionalistas han atraído mucha atención académica de excelencia. Inicialmente mezclados en una amplia red de proyectos

${ }^{10}$ Makdisi, The Culture of Sectarianism, op. cit.

${ }^{11}$ Khuri-Makdisi, The Eastern Mediterranean..., op. cit.

${ }^{12}$ Khalidi, The Origins of Arab Nationalism, op. cit.; Gelvin, Divided Loyalties, op. cit.; Keith David Watenpaugh, Being Modern in the Middle East: Revolution, Nationalism, Colonialism, and the Arab Middle Class, Princeton, Princeton University Press, 2006; Provence, The Great Syrian Revolt..., op. cit. 
reformistas - que incluían el modernismo islámico, el anarquismo obrero y el anticlericalismo cristiano-, los nacionalismos y las élites nacionalistas emergieron de las décadas de administración colonial en la región con el poder estatal en sus manos. La articulación de proyectos nacionalistas y los parámetros del debate llevan la impronta de los orígenes mixtos del nacionalismo y de su gestación en condiciones coloniales.

Ciertas figuras retóricas y sociales condensaron algunos de estos debates como puntos de tránsito obligados, aunque no necesariamente como objetos de reforma real. A principios del siglo XIX, la "mujer" emergió como tema central de debate en el Medio Oriente. Ahmed observa:

[...] el tratamiento y el estatus de la mujer se mezclaron con otros asuntos que esos intelectuales consideraron críticamente importantes para la sociedad, incluidos el nacionalismo, la necesidad del avance nacional y la reforma política, social y cultural. Desde el principio, la discusión sobre la mujer y la reforma se incrustó en consideraciones sobre el relativo avance de las sociedades europeas y la necesidad de las sociedades musulmanas de ponerse al día. Emergió un nuevo discurso sobre la mujer que se sobrepuso a las viejas formulaciones clásicas y religiosas sobre el género, más que desplazándolas, a menudo vinculando asuntos concernientes a la mujer con el nacionalismo, el avance nacional y el cambio cultural. En el nuevo, y al final del siglo, dominante discurso sobre la mujer, estos asuntos estaban íntimamente conectados. ${ }^{13}$

En muchos contextos coloniales, la posición de la mujer en la lucha nacional y, con el tiempo, en la colectividad nacional tuvo un desarrollo marcadamente ambivalente. Como Yuval-Davis observa: "A la mujer se le asigna el papel de portadora de los valores culturales, mensajera de las tradiciones y de los símbolos de la comunidad, pero 'a menudo es excluida del 'nosotros' colectivo del cuerpo político y conserva su posición de objeto más que de sujeto"..$^{14}$

Dado el molde colonial de la modernidad como fenómeno occidental y la representación de la mujer como símbolo de límites culturales por colonizadores y colonizados por igual,

${ }^{13}$ Ahmed, Women and Gender in Islam, op. cit., p. 128.

${ }^{14}$ Yuval-Davis citado en Nadje Al-Ali, Secularism, Gender, and the State in the Middle East: The Egyptian Women's Movement, Cambridge-Nueva York, Cambridge University Press, 2000. 
Abu Lughod observa que el tema de la "mujer" ha ocupado un lugar prominente en los debates sobre reformas:

En contextos coloniales o semicoloniales, la distinción entre modernidad y tradición (con su connotación de atraso) tuvo una vida particularmente activa porque fue equiparada a la distinción entre Occidente y no Occidente. Europa era moderna; Oriente no. ¿Cómo podía uno ser moderno cuando no era, no podía o no quería ser occidental?. ${ }^{15}$

La legislación poscolonial del estatus de la mujer fue una oportunidad para encarar este dilema.

El predicamento se ha institucionalizado a menudo como una división. Inspiradas en el análisis de Partha Chaterjee del contexto indio, feministas y académicos poscoloniales del Medio Oriente observan que el "estatus" de la mujer se dividió en dos esferas, una susceptible al cambio y otra ferozmente defensora de la "continuidad" o la "tradición" como algo esencialmente intocable. Por un lado, fue necesario incorporar a la mujer a la esfera pública: el campo de la educación, la representación política y el sufragio, donde la modernidad impulsó la idea de que la mujer debía participar en igualdad de condiciones con el hombre; por el otro estaba la esfera "privada", donde las relaciones maritales, el contrato matrimonial y la reproducción permanecerían inalterados. Esto creó el espacio para cultivar la continuidad cultural, donde la reforma amenazaba la sobrevivencia de la tradición y la autenticidad "árabe", "india" o "islámica".

La investigación reciente sostiene que la movilización de la mujer debe ser entendida en el contexto de la cultura política en que se incrusta. Al-Ali y Baron ${ }^{16}$ observan la participación histórica de la mujer en las luchas nacionales y anticoloniales y su fracaso en consumar proyectos como el sufragio, el bienestar femenino y los derechos reproductivos en el periodo posindependentista, incluso donde la nueva nación fue vista como "moderna" y la "cuestión de la mujer" pareció ser un punto de convergencia entre nacionalistas y movimientos femeninos. Las

${ }^{15}$ L. Abu-Lughold, Remaking Women: Feminism and Modernity in the Middle East, Princeton, Princeton University Press, 1998.

${ }^{16}$ Al-Ali, Secularism, Gender, and the State in the Middle East, op. cit.; Baron, The Women's Awakening in Egypt, op. cit. 
autoras refieren esta paradoja en términos de la "configuración de género del nacionalismo", para sugerir que las estrategias retóricas y discursivas de los proyectos nacionalistas y los posteriores proyectos de Estado reprodujeron creencias sobre los géneros que ataron a la mujer a ideales de pureza sexual, maternidad y moralidad. ${ }^{17}$ Como Yuval-Davis y Anthias han observado:

A la mujer no sólo se le ha impuesto la obligación de enseñar y transmitir las tradiciones culturales e ideológicas auténticas de la nación, sino que además a menudo se le constituye en su figuración simbólica real. Los discursos y representaciones nacionalistas describen recurrentemente a la nación como un cuerpo femenino cuya violación por extranjeros demanda de sus ciudadanos hombres salir en su defensa. ${ }^{18}$

\section{El periodo del mandato: 1919-1950}

Las administraciones del mandato establecidas en la región tras el desmembramiento del Imperio otomano, subsecuente a su participación en la primera guerra mundial, causaron al principio grandes expectativas en los nuevos agentes sociales que habían sufrido censura y represión en las últimas décadas del imperio; sin embargo, la legitimidad de las autoridades del mandato fue extremadamente frágil, y Francia y Gran Bretaña decidieron estrategias de dominación y administración que sentaron las bases de regímenes poscoloniales autoritarios de dos maneras.

Primera, la estrategia política de los Estados imperiales buscó trasplantar su propia historia de "protección” de determinadas poblaciones de la región, en la resucitada tradición otomana de mediación; esto es, establecer relaciones de estrecha colaboración con poblaciones cliente, las cuales podían funcionar como mediadoras del poder colonial. Muchos colaboradores fueron miembros de las élites de notables tradicionales otomanos, recién convertidos en propietarios privados por históricas concesiones de tierra, y enriquecidos también por su

${ }^{17}$ Al-Ali, Secularism, Gender, and the State in the Middle East, op. cit.

${ }^{18}$ Yuval-Davis citado en ibid., p. 45. 
producción para el mercado global. En otros casos, esas élites compartieron poder con poblaciones marginales en el contexto otomano, que ingresaron a la mediación colonial por su historia como clientes sectarios. Segunda, la estrategia de mediación fue complementada con ocupación militar y brutal represión de poblaciones que cuestionaban la administración colonial o la continuidad del monopolio de poder de las élites tradicionales. ${ }^{19}$

Francia combatió la Gran Revuelta Árabe con particular violencia, e intentó al mismo tiempo sobajar discursivamente un movimiento transregional e intersectario basado en asociaciones productivas y comerciales a lo que los archivos coloniales insistentemente llaman "la Revuelta Drusa" ${ }^{20}$ No obstante, como Thompson ${ }^{21}$ relata, la administración del mandato francés emprendió una guerra, cubierta y abierta, contra movimientos de mujeres que amenazaban el statu quo de una nobleza notoriamente patriarcal, así como contra movimientos obreros que hacían demandas a industriales locales y metropolitanos. Gran Bretaña y Francia desarrollaron una relación ambivalente contra los movimientos islámicos y de otra índole sectaria. Uno podría invocar las notorias negociaciones británicas con los hashemitas como pacto inestable con proyectos políticos árabes que derivaban su legitimación de la pertenencia de sus líderes a un linaje musulmán.

\section{Descolonización y revoluciones: de 1950}

\section{a la década de 1970}

Los Estados independientes establecidos en la región en la década de 1940 heredaron este panorama social. La polarización económica e ideológica de la sociedad, que el mandato agravó, y la impopularidad de las élites de notables que no sólo habían

${ }^{19}$ P. S. Khoury, Syria and the French Mandate: The Politics of Arab Nationalism, 1920-1945, Princeton, Princeton University Press, 1987; N. Méouchy et al., France, Syrie et Liban, 1918-1946: les ambiguïtés et les dynamiques de la relation mandataire, Damas, Institut Français d'Études Arabes de Damas, 2000.

${ }^{20}$ Provence, The Great Syrian Revolt..., op. cit.

${ }^{21}$ Thompson, Colonial Citizens, op. cit. 
colaborado con los regímenes coloniales sino que habían perdido la guerra árabe-israelí de 1948, provocaron una crisis de legitimidad de los líderes de los Estados poscoloniales, así como una serie de movimientos revolucionarios. ${ }^{22}$ En las décadas de 1950 y 1960 llegaron al poder grupos militares y partidos políticos de ideología socialista que desplazaron a monarcas y notables en Egipto, Siria e Iraq. ${ }^{23}$

Aunque estos regímenes revolucionarios efectuaron transformaciones institucionales significativas, ${ }^{24}$ el pacto social poscolonial de la región devino "pacto de seguridad" en el contexto del conflicto árabe-israelí. El pacto consistió en el consentimiento de los regímenes autoritarios por las clases medias, a cambio de secularismo y modernidad. Se podría argüir, siguiendo a Barreñada, ${ }^{25}$ que es precisamente el colapso de este pacto social por el debilitamiento de la riqueza petrolera y la caída de la reestructuración económica en la década de 1980, lo que está en el origen de la disputa contemporánea. ${ }^{26}$

Esas décadas sentaron las bases para una distribución particular de la disputa. En la estructura autoritaria, los partidos estatales descansaron en frentes sociales nacionalistas que podrían ser igualados a los movimientos sociales clásicos, pero que se devaluaron rápidamente por sus vínculos de subordinación al poder. Estos partidos oficiales, pese a haber sido concebidos como instrumentos de control de la población de los proyectos estatales, alojaron a grupos disidentes en su seno. ${ }^{27}$ Estos se

${ }^{22}$ Gelvin, The Israel-Palestine Conflict, op. cit.

${ }^{23}$ Hanna Batatu, The Egyptian, Syrian, and Iraqi Revolutions: Some Observations on their Underlying Causes and Social Character: Inaugural Lecture, Washington, Georgetown University, 1984.

${ }^{24}$ Centre d'Études et de Recherches sur le Moyen-Orient Contemporain: $M o u-$ vements communautaires et espaces urbains au Machreq, Beirut, CERMOC, 1985, e Industrialisation et changements sociaux dans l'Orient arabe, Beirut-Lyon, CERMOC-Presses Universitaires de Lyon, 1982.

${ }^{25}$ Isaías Barreñada, "Las revueltas árabes y el papel de los movimientos sociales”, ponencia presentada en la conferencia Segunda Semana Árabe en México, México, 2011.

${ }^{26}$ P. Fargues: Les champs migratoires internes en Syrie, Beirut-Lyon, CERMOCPresses Universitaires de Lyon, 1979, y Réserves de main-d'œuvre et rente pétrolière : étude démographique des migrations de travail vers les pays arabes $d u$ golfe, Beirut-Lyon, CERMOC-Presses Universitaires de Lyon, 1980.

${ }^{27}$ Barreñada, "Las revueltas árabes y el papel de los movimientos sociales”, op. cit. 
convirtieron en una especie de refugio para los impugnadores de izquierda, que agruparon facciones frustradas dentro de las organizaciones nacionalistas oficiales.

Dada la cultura política autoritaria de los Estados poscoloniales, que imposibilitó el debate público y la participación política fuera de las redes clientelares, y dado el limitado éxito de los esfuerzos de los regímenes revolucionarios y monárquicos por redistribuir los recursos en pos del bienestar social, los últimos treinta años resultaron en el renacimiento del islam como lenguaje de la impugnación en la región. La disidencia que permaneció fuera del Estado, visible como oposición perseguida, es el fenómeno múltiple que ha sido etiquetado como islam político. Sin olvidar el papel aglutinador de las órdenes sufíes en varias luchas antiimperialistas del siglo XIX y la fundación de la Hermandad Musulmana, en Egipto, en 1928, es fácil reconocer que en las décadas de consolidación poscolonial emergieron nuevas formas y discursos de resistencia que afirmaban ser "islámicos" en diversas formas. ${ }^{28}$

El éxito de la revolución iraní en particular inspiró la reelaboración del discurso islámico y dio nueva legitimidad a quienes aspiraban a la islamización del Estado como proyecto de liberación antiimperialista. ${ }^{29} \mathrm{El}$ islamismo emergió como respuesta ideológica, pero también como solución práctica. En varios contextos, los movimientos islámicos han ofrecido fuentes alternativas de servicios públicos donde el Estado está ausente, desde infraestructura urbana básica en áreas marginadas, hasta educación, salud y medios de comunicación satelital. ${ }^{30}$ Ofrecen también universos mediáticos, que constituyen, a ojos de algunos analistas, una esfera pública islámica que opera de manera paralela y subalterna, aunque algunas de las teledi-

${ }^{28}$ E. Burke, I. M. Lapidus et al., Islam, Politics and Social Movements, Berkeley, University of California Press, 1988; Dale F. Eickelman y James P. Piscatori, Muslim Politics, Princeton Studies in Muslim Politics, Princeton, Princeton University Press, 1996.

${ }^{29}$ N. R. Keddie, Modern Iran: Roots and Results of Revolution, New Haven, Yale University Press, 2006.

${ }^{30} \mathrm{D}$. El-Bizri, L'ombre et son double : femmes islamistes, libanaises et modernes, Beirut, CERMOC, 1995; Mona Harb El-Kak, Politiques urbaines dans la banlieue-sud de Beyrouth, Beirut, CERMOC, 1996; Mona Harb El-Kak, Le Hezbollah à Beyrouth (19852005): de la banlieue à la ville, París, Karthala, 2010. 
fusoras estatales ofrezcan programas conducidos por islamistas, como es el caso de Qaradawi en al-Jazeera. ${ }^{31}$

Es importante tener en mente que el fin de siglo islámico es un discurso que se nutre de historias regionales, pero que también es conformado por transformaciones globales que han transfigurado la práctica de todas las tradiciones religiosas desde la última mitad del siglo Xx..$^{32}$ Los desplazamientos de localización de la autoridad religiosa debidos a la nueva familiaridad cotidiana con los textos religiosos fundacionales, posibilitada por la alfabetización masiva, sustenta proyectos tales como los feminismos islámicos estudiados en Egipto y Líbano por Mahmood y Deeb respectivamente. ${ }^{33}$ Caracterizados por una política devocional que introduce intereses colectivos en la búsqueda de una subjetividad modelo, estos movimientos se abocan a la educación en valores islámicos y el cultivo personal del yo devoto. En la medida en que buscan construir una realidad cotidiana saturada de islam, más allá y hasta en contra del Estado, estos movimientos implican riesgos para la autoridad de éste y la legitimidad de su regulación de la vida social.

\section{Nuevos movimientos sociales: 1980-2011}

Mientras el islam y la reislamización se convertían en vectores privilegiados de la disidencia pública y alternativas organizadas institucionalizadas, también se desarrolló un amplio conjunto de movimientos seculares. Las tendencias cambiantes de la dinámica geopolítica desde la caída del mundo socialista se constituyeron en un nuevo y crucial entramado de la acción. Sobre

${ }^{31}$ Eickelman y Piscatori, Muslim Politics, op. cit.; Dale F. Eickelman y J. W. Anderson, New Media in the Muslim World: The Emerging Public Sphere, Bloomington, Indiana University Press, 2003; y Hefner, Remaking Muslim Politics, op. cit.

${ }^{32}$ Talal Asad, The Idea of an Anthropology of Islam, Washington, Georgetown University, 1986; R. W. Hefner, "Multiple Modernities: Christianity, Islam, and Hinduism in a Globalizing Age", Annual Review of Anthropology, vol. 27, 1998, pp. 83-104; R. W. Hefner, Remaking Muslim Politics: Pluralism, Contestation, Democratization, Princeton, Princeton University Press, 2005.

${ }^{33}$ Saba Mahmood, Politics of Piety: The Islamic Revival and the Feminist Subject, Princeton, Princeton University Press, 2005; L. Deeb, An Enchanted Modern: Gender and Public Piety in Shi'i Lebanon, Princeton, Princeton University Press, 2006. 
todo en Estados que adoptaron políticas de liberalización o de ajuste estructural que disminuyeron sus soluciones a problemas sociales, o que abandonaron de plano su compromiso social, se organizó un resurgimiento de la movilización mediante nuevas formas institucionales. Esta evolución creó contradicciones a medida que amplió horizontes para la movilización. ${ }^{34}$

Igual que en los debates nacionalistas del paso al siglo XIX, en los del Medio Oriente de hoy las mujeres ocupan una posición ambigua: "Atrapadas entre la búsqueda de la modernización, los intentos de liberalización y la muy difundida retórica de la 'autenticidad' y la intrusión imperialista, las mujeres a menudo son el foco de ambiguos intereses en conflicto". ${ }^{35} \mathrm{De}$ acuerdo con Al-Ali, el activismo femenino egipcio contemporáneo está "mucho más conformado por el temor a transgredir normas y valores imbricados en el tejido social". ${ }^{36}$ A medida que se abrieron espacios de organización para diversos agentes sociales, las tensiones entre proyectos de reforma diferentes emergieron una vez más.

Con buen uso de los discursos de derechos humanos en la arena internacional y de la diseminada forma institucional organización no gubernamental, las organizaciones defensoras de "derechos" de minorías y de otras poblaciones vulnerables se multiplicaron a partir de la década de 1980: organizaciones no gubernamentales de mujeres, estudiantes, grupos étnicos, de refugiados y proyectos de desarrollo local.

Estas formas institucionales también sirvieron como refugio relativamente seguro de activistas que no podían expresarse públicamente por sí mismos. Aunque buscan generar transformación social, estas alternativas no usan lenguajes de

${ }^{34} \mathrm{~J}$. T. Chalcraft, The Invisible Cage: Syrian Migrant Workers in Lebanon, Stanford, Stanford University Press, 2008; F. Ghannan, Remaking the Modern: Space, Relocation, and the Politics of Identity in a Global Cairo, Berkeley, University of California Press, 2002; H. Jaber y F. Métral, Mondes en mouvement : migrants et migrations au Moyen-Orient au tournant du XXI siècle, Beirut, IFP, 2005; Paul A. Silverstein, Algeria in France: Transpolitics, Race, and Nation, Bloomington, Indiana University Press, 2004; D. Singerman, Avenues of Participation: Family, Politics, and Networks in Urban Quarters of Cairo, Princeton, Princeton University Press, 1995; D. Singerman y H. Hoodfar, Development, Change, and Gender in Cairo: A View from the Household, Bloomington, Indiana University Press, 1996.

${ }^{35}$ Al-Ali, Secularism, Gender, and the State in the Middle East, op. cit., p. 1.

${ }^{36}$ Ibid., p. 2. 
impugnación. A veces organizadas en torno de causas específicas, como las de prisioneros, desparecidos o víctimas de accidentes laborales, estas formas se volvieron cada vez más activas, crearon redes y emergieron como arena de experimentos de coordinación de la movilización. La confrontación con el Estado nunca estaba demasiado lejos, pues movilizarse por la causa palestina en el Egipto de Sadat o de Mubarak era también una manera de movilizarse contra el Estado. ${ }^{37}$

El bajo y lento crecimiento económico en las condiciones neoliberales acentuó las desigualdades y la exclusión de amplios sectores sociales, condiciones agravadas por el boom demográfico posterior a la independencia. La creciente conciencia de esta desigualdad es producto parcial de reformas revolucionarias: la elevación de niveles de vida, la ampliación de la educación, la incorporación de la mujer a la fuerza de trabajo asalariada, la ampliación de la edad de matrimonio; procesos que han tenido profundas consecuencias en la estructura de la familia y en las expectativas económicas y sociales.

Aunque los proyectos del Estado poscolonial cultivaron con esmero la excepcionalidad de la mujer, también establecieron la educación masiva y crearon empleo público. La alfabetización y la movilidad social empujaron a amplios sectores rurales y urbanos hacia la clase media, que llegó a influir la producción cultural en todos los niveles. Como nota Ahmed, "No sólo fue que la cultura predominante y sus discursos fueran articulados ahora por una amplia base social, sino que fueran conformados por un significativo número de mujeres. La televisión, el cine y los estilos de vestir reflejaron la cambiada demografía de la producción cultural y de los discursos predominantes". 38

Estas condiciones resultaron en un amplio repertorio de alternativas creadas por mujeres militantes en términos de actividad y organización institucional.

Como en otras partes, hoy los grupos de mujeres en Egipto, sus niveles de independencia y libertad de acción, número de miembros, composición de clase y afiliación nacional e inter-

\footnotetext{
${ }^{37}$ Barreñada, "Las revueltas árabes y el papel de los movimientos sociales", op. cit.

${ }^{38}$ Ahmed, Women and Gender in Islam, op. cit., p. 214.
} 
nacional, varían: "el terreno del compromiso político abarca desde el trabajo social y de desarrollo hasta la formación de conciencia en seminarios, conferencias, grupos de discusión, promoción de actividades de investigación, campañas y publicación de panfletos, revistas y libros". ${ }^{39}$

Más allá de la cuestión de género, la región presenta una población abrumadoramente joven, la cual incluye más de la mitad de los desempleados, los migrantes y los participantes en las revueltas y revoluciones en curso. La región se caracteriza por altos niveles de "trabajo con pobreza": trabajo con remuneración inadecuada, empleo informal y altas tasas de desempleo juvenil. La falta de oportunidades de trabajo afecta a los jóvenes educados, quienes han creado asociaciones y movimientos de universitarios graduados desempleados en busca de una reestructuración de la participación política y económica.

Aun en las difíciles condiciones de los últimos años, casos de acción colectiva de visible gran escala, como la crisis del área minera de Gafsa, en Túnez, y la huelga de Mahalla Al-Kubra, en Egipto, ambas en 2008, forzaron a las autoridades a responder con medidas de alivio, y contribuyeron a crear una cultura de protesta y una ciudadanía consciente, como Barreñada ha observado. ${ }^{40}$ Ambos casos hicieron visibles las condiciones de pobreza y marginación experimentadas en ciudades de provincia de la región, espacios que frecuentemente escapan a la mirada internacional.

\section{Mujeres en revuelta e interlocutores islamistas}

La cobertura mediática de la participación de la mujer en las revueltas recientes revela distancias y sinergias significativas entre las interpretaciones locales y las euroamericanas de la movilización actual, especialmente si su acción política es seguida por la prensa on line árabe e internacional. La omnipresencia de las mujeres en las protestas y su cobertura suscitan lecturas contradictorias. Algunos temas emergidos en las representaciones

${ }^{39}$ Al-Ali, Secularism, Gender, and the State in the Middle East, op. cit., p. 11.

${ }^{40}$ Barreñada, "Las revueltas árabes y el papel de los movimientos sociales", op. cit. 
mediáticas presentan incómodos puntos de confluencia entre el discurso global emancipador de la sociedad civil y los derechos humanos con orientalismos exuberantes.

Destacan tres tendencias. Primera, la mujer continúa poniendo barómetros de civilidad, señas de secularidad y sus descontentos. Segunda, el énfasis mediático en paralelos con figuras simbólicas de la liberación femenina en "Euroamérica" representa a la mujer militante del Medio Oriente como imitadora informada y deseosa de seguir el camino "occidental" de la modernidad femenina. El hecho de que las mujeres árabes se apropien a veces de símbolos feministas euroamericanos es fascinante. Tercera, en la cobertura mediática, las acciones de las mujeres a menudo son despojadas de su dimensión radical, lo que reduce los gestos políticos a tradiciones de color local. Estos hilos de interpretación se mezclaron en los medios euroamericanos, que en un principio presentaron a las mujeres oprimidas en revuelta como celebrantes de la revolución eurocéntrica, sólo para angustiarse por el "giro islamista" que ahora amenaza las libertades femeninas.

La presencia vocal de la mujer en las protestas marcó a los movimientos como civiles, modernos y finalmente legítimos e inteligibles para la audiencia global, pero los medios de comunicación representaron su activismo y visibilidad como ruda conmoción para el mundo “civilizado". En 2011, por ejemplo, Montreal Gazzette y Canadian National Post reconocieron: "En enero, mujeres egipcias asombraron al mundo al tomar las calles junto con hombres para derribar el régimen corrupto de Mubarak". ${ }^{41}$ Der Spiegel se congratuló, al inicio, por la prominente presencia de mujeres:

Su participación transmite una nueva imagen de la juventud y las mujeres árabes. Los muchos fotógrafos en El Cairo y Túnez enviaron a sus editoriales imágenes de atractivas mujeres tomando parte en la revolución.

La gente de Occidente se reconoció en los rostros de las jóvenes manifestantes y se sintió complacida de que la gente de esos países no sea tan diferente, como muchos han creído. La certeza de que los árabes son incompatibles con la democracia fue destruida, igual que el cliché

${ }^{41}$ Bagnall, Janet, "Women’s Gains in Arab Spring more Mirage than Miracle”, National Post, 16 de diciembre de 2011, y "Women's Gains in Arab Spring more Mirage than Miracle”, Montreal Gazette, 18 de diciembre de 2011. 
de la mujer árabe pasiva y oprimida. Ninguna de las insurrecciones de los países árabes habría sido posible sin la participación de mujeres. Ellas estuvieron entre las primeras en protestar en la Plaza de la Perla en Bahréin, organizaron protestas femeninas en Siria, fueron parte de la insurrección libia desde el principio, y una activista yemení fue una de las ganadoras del Premio Nobel de la Paz ese año. ${ }^{42}$

La presencia pública de la mujer fue tranquilizadora para los públicos eurocéntricos, que podían interpretarla como indicio de que, después de todo, los árabes y los musulmanes no eran diferentes a los europeos: décadas de descripciones mediáticas derogatorias se revelaron de súbito como clichés, argumentos políticos eruditos sobre choques de civilizaciones e incompatibilidades, que se derrumbaron ante los jóvenes rostros femeninos en pos de la justicia social.

Por Internet circuló un cartón sobre una mujer, Marianne, en tenis, sexy, pero de perfil ligeramente musulmán; fusil en mano y una bandera turca en alto contra un horizonte turbulento de minaretes; encabezaba a mujeres con camisetas de Facebook, armadas con teléfonos móviles, cimitarras y rifles en un encarnizado campo de batalla. Firmando como "Chappatte, pardon a Delacroix", el cartonista suizo-libanés Patrick Chapatte usó la célebre pintura La libertad guiando al pueblo, de Delacroix, 1830, para presentar las revueltas del norte de África como herederas de la fundadora revolución francesa, y su encarnación femenina, Marianne, en la resultante república (francesa). Inicialmente publicado en Les Temps de Ginebra, donde Chapatte publica habitualmente, el cartón fue incorporado a artículos en la red, por ejemplo, "An Arab Spring for Women?", de Lina Abou Habib. ${ }^{43}$

A la estética republicana francesa se unieron on line dos figuras clave de la historia de la mujer estadounidense, Rosie la remachadora y las bra burners. Cartel de 1942 vuelto símbolo del feminismo estadounidense, Rosie la remachadora es una hermosa y severa mujer joven en ropa azul de fábrica y rizos recogidos con paño de puntos rojos y blancos, que muestra

\footnotetext{
${ }^{42}$ Mathieu von Rohr, "Freedoms at Risk. Arab Women Fight to Defend their Rights”, Spiegel Online. International, 29 de noviembre de 2011.

${ }^{43}$ Lina Abou Habib, “An Arab Spring for Women?”, Making It Magazine.Net Industry for Development, 23 de junio de 2011.
} 
un fuerte bíceps, contra un trasfondo amarillo brillante y una leyenda gigantesca que dice "We can do it" en blanco sobre azul. Figura de propaganda industrial de la segunda guerra mundial para mantener la moral y alentar a la mujer a unirse a la fuerza de trabajo en el esfuerzo de guerra, la imagen de Rosie la remachadora fue apropiada por el movimiento feminista estadounidense de la década de 1980 como símbolo de empoderamiento. Fue reinterpretada durante las revueltas por el diseñador gráfico saudí Ruba al-Yamani para representar a Manal al-Sharif, diligentemente acicalada con vestimenta abaya negra y un diáfano velo niqab en su rostro, con la leyenda: "Podemos hacerlo, podemos conducir", referencia al activismo de Manal en defensa del derecho de la mujer a manejar en Arabia Saudita. Carteles de una dulce y firmemente sonriente joven Asmaa Mahfouz, vistiendo hijaby con lentes, a quien se atribuye haber iniciado la revolución egipcia, fueron realizados con estética similar por Graphic Resistance, deviantart.com.

La quema de brasieres, atribuida a feministas radicales que impugnaban reglas patriarcales en Estados Unidos a fines de la década de 1970, fue un gesto inspirado por la quema de cartillas de reclutamiento por jóvenes durante las protestas contra la guerra de Vietnam. El gesto tuvo eco en las imágenes de quema de velos que recorrieron el mundo a través de la prensa a principios de noviembre de 2011, que mostraban a mujeres yemeníes cuidadosamente cubiertas con velos, con gorras de béisbol y otros velos ardiendo en los bates. Estas apropiaciones de símbolos feministas estaban acordes con el potencial de "liberación” que las revueltas portaban, como las imágenes de matronas disparando kalashnikovs al cielo de Libia, o jóvenes mujeres entonando consignas revolucionarias, el logo del Live Syria Blog de Al-Jazeera, una joven vistiendo hijab blanca, la bandera siria como cinta en la cabeza y banderas pintadas en ambas mejillas y en la nariz, cejas arrugadas, ojos cerrados al cantar y sonrisa en sus labios, imágenes que fueron transmitidas a un mundo expectante.

Intensas descripciones gráficas de celebración, incontables imágenes de mujeres envueltas en banderas nacionales y manos con la consigna Irbal (¡Largo, váyanse!) en caligrafía fueron publicadas por la prensa internacional, a menudo acompañadas de 
leyendas incongruentes. ${ }^{44}$ Las imágenes de manos de muchachas pintadas con colores de banderas nacionales y la frase al-nasr al-sheub, la victoria de los pueblos, fueron editadas por Reuters con textos alusivos a la tradición: "En una fiesta vespertina de preboda, en Trípoli, un grupo de mujeres libias entona canciones tradicionales al ritmo de un tambor, mientras se disponen a frotar henna en las manos y pies de la novia". ${ }^{45}$

Imágenes de mujeres yemeníes quemando velos fueron glosadas como símbolos tradicionales confrontados con la represión moderna por Hani Mohammed de The Washington Post. ${ }^{46}$ Por un lado, el pie de foto dice que cientos de mujeres quemaron sus velos en Sanaa, capital de Yemen, en protesta por la brutal represión gubernamental de quienes demandaban la salida del presidente Saleh, pero la nota explica con orgullo que "la quema de ropa por mujeres es un gesto simbólico beduino que significa petición de ayuda a los hombres de la tribu". Esta lectura tradicional fue reproducida, junto con las imágenes de quema de velos, por medios digitales independientes. ${ }^{47} \mathrm{La}$ poderosa e innovadora protesta política de la mujer a lo largo del mundo árabe fue reducida a tradicionales noches de henna en las que se decoran manos y pies de las novias, costumbres tradicionales de relaciones tradicionales.

La participación en las revueltas de 2011 trajo premios y castigos para las mujeres que protestaron. Entre los honores más altos está el Premio Nobel de la Paz a Tawakkol Karman, mujer activista yemení, periodista y líder del grupo de derechos humanos Mujeres Periodistas sin Cadenas. De acuerdo con el diario español El País, Thorbjorn Jagland, presidente del comité noruego, declaró que el premio a Karman debía ser considerado:

[...] signo de que la mujer así como el islam tienen importantes papeles en la insurrección conocida como Primavera Árabe [...] La Primavera

\footnotetext{
${ }^{44}$ Rosemary D’Amour, “As Arab Spring turns to Winter, Women Fear Pushback", Nation of Change, 5 de noviembre de 2011.

${ }^{45}$ Marie-Louise Gumucian, “Arab Spring puts Women’s Rights in the Spotlight”, Reuters, 20 de diciembre de 2011.

${ }^{46}$ Hani Mohammad, "Yemeni Women burn Veils in Protest", The Washington Post, 26 de octubre de 2011.

${ }^{47}$ Mary Elizabeth King, "Traditional Symbols confront Modern Repression”, Waging Nonviolence. People Powered News and Analysis, 6 de noviembre de 2011.
} 
Árabe no puede tener éxito sin incluir a la mujer [...] Jagland añadió que Karman, de 32 años, pertenece a un movimiento musulmán asociado a la Hermandad Musulmana, el grupo islámico que en Occidente es percibido como amenaza a la democracia. Pero "no lo creo", añadió. Hay muchos indicios de que esta clase de movimientos pueden ser una parte importante de la solución. ${ }^{48}$

El 2 de noviembre, el Subcomité de Operaciones y Organizaciones Internacionales, Derechos Humanos, Democracia y Asuntos Globales de la Mujer y el Subcomité de Asuntos del Cercano Oriente y Sur Central de Asia, discutieron la participación de la mujer en la Primavera Árabe con el Senado de Estados Unidos, y reconocieron su prominencia.

Entre las represalias más notorias contra mujeres se encuentra la violencia de Estado, que en algunos casos tomó la forma de violencia sexual y ultraje. Se reportó que la policía aplicó "pruebas de virginidad" a las mujeres que protestaban en Egipto. Der Spiegel reportó que "Mona Eltahawy, quien participó en las protestas de la plaza, fue detenida durante horas con los ojos vendados. Los oficiales la palparon y le fracturaron los brazos y una mano". Ellos "tocaron y pincharon mis senos, tocaron mis genitales y perdí la cuenta de las manos que intentaron tocar bajo mi ropa interior", escribió en Twitter. "Son perros y sus jefes son perros". ${ }^{49}$ Un video y fotografías de oficiales de policía golpeando y arrastrando brutalmente a una joven con velo por la calle, exponiendo su brasier azul brillante, provocaron una inmediata movilización de indignación de las activistas de Egipto en protesta contra la violencia sexual.

La participación de la mujer en la más reciente ola de revueltas y revolución en el moderno Medio Oriente consolidó a un puñado de heroínas regionales, desde las celebridades políticas Asmaa, Manal y Tawakkul, hasta la estudiante de arte de la Universidad Americana de El Cairo, Aliaa Magda Elmahdy, cuyo blog, en el que puso una fotografía de sí misma desnuda en desafío a las peticiones conservadoras de cubrir los cuerpos femeninos, atrajo innumerables visitantes. La participación

${ }^{48}$ El País, “Tres mujeres ganan el Premio Nobel de la Paz”, El Pais.com.co, 7 de octubre de 2011.

${ }^{49}$ Von Rohr, "Freedoms at Risk. Arab Women Fight to Defend their Rights", op. cit. 
de la mujer resultó también en la creación de nuevas redes y una coordinación sin precedentes entre activistas.

Conforme proceden las elecciones en la región y los partidos políticos islámicos, como la Hermandad Musulmana de Egipto, confrontan al liderato militar renuente a dejar el poder para bien, se multiplican los discursos euroamericanos que rechazan a los islamistas como interlocutores políticos emergentes. En vez de considerar a los islamistas - única oposición política organizada en muchos países - como parte de la solución a la desigualdad, el desempleo y la falta de participación política, como el comité del Premio Nobel admitió hace unos cuantos meses, los formadores de opinión hablan ahora de las libertades de la mujer y de los derechos humanos amenazados:

En enero, mujeres egipcias impresionaron al mundo al tomar las calles junto con hombres para hacer caer al régimen corrupto de Mubarak. Con sus gafas de diseño y bufandas estampadas de flores, ganaron el corazón de la gente de todo el mundo. Desafiaron las armas y se opusieron a las "pruebas de virginidad" decretadas por los militares. Gente de todas partes las alentó, deseando que ganen la libertad para ellas y la democracia para su país.

Casi un año después, el brillante futuro de las mujeres que las revoluciones de la Primavera Árabe del norte de África y el Medio Oriente parecían prometer, parecía más espejismo que milagro..$^{50}$

$\mathrm{Al}$ parecer, los afanosos consumidores euroamericanos asumieron que las preferencias comunes de compras, como las gafas de diseño, entrañan proyectos políticos comunes. Como Mathieu von Rohr denunció dramáticamente en el artículo "Freedoms at Risk", publicado en Der Spiegel a fines de noviembre de 2011, "Fue un error creer que el mundo árabe se volvería más occidental después de las revoluciones. Al contrario, los residentes de muchos lugares están volviendo hacia sus propios valores". ${ }^{51}$ Declaraciones como ésta evidencian la distancia entre los movimientos árabes y su ambivalente lectura euroamericana.

Sin embargo, la base común sigue siendo parte del discurso sobre el nuevo Medio Oriente, como lo sugieren dos significa-

\footnotetext{
${ }^{50}$ Bagnall, "Women's Gains in Arab Spring more Mirage than Miracle", op. cit.

${ }^{51}$ Von Rohr, "Freedoms at Risk. Arab Women Fight to Defend their Rights", op. cit.
} 
tivas imágenes. Una, la portada de la revista Time al anunciar a la Persona Time del Año, El Manifestante, que caracteriza a un personaje perfectamente ambiguo, acaso mujer, probablemente joven, con la cabellera cubierta por un grueso sombrero de invierno, el rostro cubierto con una bufanda color beige y un par de ojos café claro mirando fijamente, con una leyenda que reúne las protestas del año en una escena global única: De la Primavera Árabe a Atenas, de Occupy Wall Street a Moscú. La otra, la foto de World Press, premiada en 2011, del joven fotógrafo español Samuel Aranda, por la dramática imagen de un rebelde yemení herido en brazos de una mujer, tan cubierta de ropajes negros que sólo se aprecia el puente de su nariz, mientras sostiene al rebelde en sus manos cubiertas con guantes quirúrgicos en una perfecta pieta: la imagen cristiana clásica de Cristo muerto en brazos de su madre.

\section{Conclusión}

Lo que emerge claramente de la historia de la movilización en el Medio Oriente moderno es que las revueltas contemporáneas están firmemente ancladas en una tradición de movilización social, en prácticas resurgentes que construyen redes asociativas con diversas capacidades para la protesta social. En breve, el Medio Oriente se ufana de una sociedad civil activa con una historia moderna. La precipitación de la movilización masiva en 2011 sólo es comprensible contra el trasfondo de procesos que han conformado un liderato, así como una organización diseminada, una diversidad de centros de operación, medios de comunicación y contactos con el exterior.

La coalición de diversos agentes sociales que ha caracterizado a los movimientos de la Primavera Árabe o Thaurat alShaeb, la Revolución del Pueblo, el desplazamiento del conflicto árabe-israelí y de las agendas islámicas por demandas sociales y económicas como eje del discurso regional de movilización, son reminiscentes de las dinámicas de movilización de principios del siglo XIX. Una movilización con una diversidad llena de posibilidades fue paralizada por las intervenciones autoritarias de un Estado colonial y luego poscolonial. 
Más allá de las dificultades inherentes a todo proceso posrevolucionario - los desafíos de crear y sostener consensos y de institucionalizar coaliciones que integren efectivamente los intereses y proyectos de una oposición diversa-, ciertas intervenciones de las posiciones de poder han sido perturbadoras. En el caso de Israel, tan pronto como las movilizaciones internas en demanda de empleo, mejores salarios y acceso a vivienda - y llamando a una "Tentifada" - ganaron momento, tan pronto como la Primavera Árabe atrajo a jóvenes israelíes, se reportaron "violentos incidentes" en la frontera de Israel con Egipto. Las autoridades de Tel Aviv sofocaron los intentos de movilización a principios del verano de 2012, pero más que el control municipal efectivo, el llamado a la unidad nacional frente a conocidos enemigos externos desvió el viento de las velas de la Tentifada; la escalada de amenazas de guerra por oficiales israelíes contra Irán y, más recientemente, contra Líbano han cultivado el fantasma de la guerra el último año.

En Egipto, a su vez, mientras la dinámica de Tahrir cuajó en la articulación de una demanda colectiva que nada tenía que ver con la tradición religiosa, la proximidad de las elecciones precipitó una andanada de ataques contra la población y espacios coptos. Esto es, cuando los militares que "advirtieron" la transición tuvieron que enfrentar la realidad de dejar el poder, la invocación de reyertas sectarias apareció como un obstáculo conveniente; habría sido irresponsable "dejar libre" a una población religiosamente diversa enfilada hacia la guerra civil.

En última instancia, la cuestión de cómo los líderes asumen el liderato en la región a raíz de la crisis actual es tan importante como la cuestión de quiénes son ellos mismos. Las elecciones han arrojado resultados muy diferentes en los países. El éxito electoral de los islamistas en Egipto no sorprende si en la elección presidencial los votantes sólo tuvieron la opción de votar por Mursi, hermano musulmán moderado y educado, o entregar el poder a un candidato estrechamente asociado a los militares y al régimen impugnado. En una elección tan cerrada, tal voto podría significar el rechazo al pasado más que un compromiso con la islamización. 
Los partidos islamistas han sido exitosos también en Túnez, pero no en Libia. Es importante notar que en todos estos contextos el vehículo de la distribución de poder ha sido el sufragio, y los representantes electos están obligados a operar políticamente mediante los mecanismos de la legalidad electoral. A diferencia de los líderes teocráticos de la revolución iraní o del control wahabí de Arabia Saudita, que introdujo las ortodoxias de gobierno islámico como consecuencia inevitable de la permanencia de musulmanes devotos en el poder, como apuntan los analistas, los partidos islamistas deben compartir el poder con otros y llegar a compromisos. Los islamistas del siglo XXI electos para puestos de liderazgo en el norte de África responderán más como los islamistas electos en Turquía o Líbano, donde se les ha permitido participar en contiendas electorales desde mucho antes. ${ }^{52}$ Tendrán que negociar, igual que cualquier otro líder electo.

\section{Traducción del inglés: Ramón Cota Meza}

Dirección institucional de la autora:

División de Historia

Centro de Investigación y Docencia Económicas

Carretera México-Toluca 3655

Lomas de Santa Fe

Del. Álvaro Obregón

01210, México, D.F.

$\triangle$ camila.pastor@cide.edu

\section{Bibliografía}

Aвоu Habib, Lina, "An Arab Spring for Women?", Making It Magazine.Net Industry for Development, 23 de junio de 2011. [makingitmagazine.net.]

Abu-Lughod, L., Remaking Women: Feminism and Modernity in the Middle East, Princeton, Princeton University Press, 1998.

AHMED, Leila, Women and Gender in Islam: Historical Roots of a Modern Debate, New Haven, Yale University Press, 1992.

${ }^{52}$ D. El-Bizri, Islamistes, parlementaires et Libanais, Beirut, CERMOC, 1999. 
Al-Ali, Nadje, Secularism, Gender, and the State in the Middle East: The Egyptian Women's Movement, Cambridge-Nueva York, Cambridge University Press, 2000.

AsAD, Talal, The Idea of an Anthropology of Islam, Washington, Georgetown University, 1986.

Bagnall, Janet, "Women's Gains in Arab Spring more Mirage than Miracle", National Post, 16 de diciembre de 2011. [news. nationalpost.com/2011/12/16/womens-gains-in-arab-springmore-mirage-than-miracle/.]

Bagnall, Janet, "Women's Gains in Arab Spring more Mirage than Miracle”, Montreal Gazette, 18 de diciembre de 2011. [montrealgazette.com/news/Arab + Spring + Women + line + fire/5874208/ story.html.]

BARON, Beth, The Women's Awakening in Egypt: Culture, Society, and the Press, New Haven, Yale University Press, 1994.

BARREÑADA, Isaías, "Las revueltas árabes y el papel de los movimientos sociales", ponencia presentada en la conferencia Segunda Semana Árabe en México, México, 2011.

Batatu, Hanna, The Egyptian, Syrian, and Iraqi Revolutions: Some Observations on their Underlying Causes and Social Character: Inaugural lecture, Washington, Georgetown University, 1984.

BeInIN, J, Workers and Peasants in the Modern Middle East, Cambridge, Nueva York, Cambridge University Press, 2001.

BeInIN, J. y Z. Lockman, Workers on the Nile: Nationalism, Communism, Islam, and the Egyptian Working Class, 1882-1954, Princeton, Princeton University Press, 1987.

Bourgey, A., Migrations et changements sociaux dans l'Orient arabe, Beirut, CERMOC, 1985.

Burke, E., I. M. Lapidus et al., Islam, Politics and Social Movements, Berkeley, University of California Press, 1988.

ÇELIK, Zeynep, Empire, Architecture, and the City: French-Ottoman Encounters, 1830-1914, Seattle, University of Washington Press, 2008.

Centre d'Études et de Recherches sur le Moyen-Orient Contemporain, Industrialisation et changements sociaux dans l'Orient arabe, Beirut-Lyon, CERMOC-Presses Universitaires de Lyon, 1982.

Centre d'Études et de Recherches sur le Moyen-Orient Contemporain, Mouvements communautaires et espaces urbains au Machreq, Beirut, CERMOC, 1985.

Chalcraft, J. T., The Invisible Cage: Syrian Migrant Workers in Lebanon, Stanford, Stanford University Press, 2008. 
Cleveland, William L., A History of the Modern Middle East, Boulder, Westview Press, 1994.

D’Amour, Rosemary, "As Arab Spring turns to Winter, Women Fear Pushback", Nation of Change, 5 de noviembre de 2011. [nationofchange.org/arab-spring-turns-winter-women-fearpushback-1320504635.]

Deeb, L., An Enchanted Modern: Gender and Public Piety in Shi'i Lebanon, Princeton, Princeton University Press, 2006.

EIcKelman, D. F. y J. W. Anderson, New Media in the Muslim World: The Emerging Public Sphere, Bloomington, Indiana University Press, 2003.

Eickelman, Dale F. y James P. Piscatori, Muslim Politics, Princeton Studies in Muslim Politics, Princeton, Princeton University Press, 1996.

El País, “Tres mujeres ganan el Premio Nobel de la Paz”, El Pais.com. co, 7 de octubre de 2011. [elpais.com.co/elpais/internacional/ noticias/tres-mujeres-ganan-premio-nobel-paz.]

EL-BIZRI, D., Islamistes, parlementaires et Libanais, Beirut, CERMOC, 1999.

EL-BIZRI, D., L'ombre et son double: femmes islamistes, libanaises et modernes, Beirut, CERMOC, 1995.

FARGUES, P., Les champs migratoires internes en Syrie, Beirut-Lyon, CERMOC-Presses Universitaires de Lyon, 1979.

FARGUES, P., Réserves de main-d'ouvre et rente pétrolière : étude démographique des migrations de travail vers les pays arabes $d u$ golfe, Beirut-Lyon, CERMOC-Presses Universitaires de Lyon, 1980.

FaWAZ, L. T., Merchants and Migrants in Nineteenth-century Beirut, Cambridge, Harvard University Press, 1983.

Gelvin, James L., Divided Loyalties: Nationalism and Mass Politics in Syria at the Close of Empire, Berkeley, University of California Press, 1998.

Gelvin, James L., The Israel-Palestine Conflict: One Hundred Years of War, Cambridge, Cambridge University Press, 2005.

Ghannam, F., Remaking the Modern: Space, Relocation, and the Politics of Identity in a Global Cairo, Berkeley, University of California Press, 2002.

Gualtieri, S. M. A., Between Arab and White: Race and Ethnicity in the Early Syrian American Diaspora, Berkeley, University of California Press, 2009.

Gumuchian, Marie-Louise, “Arab Spring Puts Women's Rights in the Spotlight", Reuters, 20 de diciembre de 2011. [in.reuters.com/article/2011/12/20/us-arabs-women-idINTRE7BJOQW20111220.] 
Harb EL-KaK, Mona, Politiques urbaines dans la banlieue-sud de Beyrouth, Beirut, CERMOC, 1996.

Harb El-KaK, Mona, Le Hezbollah à Beyrouth (1985-2005) : de la banlieue à la ville, París, Karthala, 2010.

Hefner, R. W., "Multiple Modernities: Christianity, Islam, and Hinduism in a Globalizing Age", Annual Review of Anthropology, vol. 27, 1998, pp. 83-104.

Hefner, R. W., Remaking Muslim Politics: Pluralism, Contestation, Democratization, Princeton, Princeton University Press, 2005.

JABER, H. y F. Métral, Mondes en mouvement: migrants et migrations au Moyen-Orient au tournant du XXI siècle, Beirut, IFP, 2005.

Keddie, N. R., Modern Iran: Roots and Results of Revolution, New Haven, Yale University Press, 2006.

KHALIDI, R., The Origins of Arab Nationalism, Nueva York, Columbia University Press, 1991.

Khater, A. F., Inventing Home: Emigration, Gender, and the Middle Class in Lebanon, 1870-1920, Berkeley, University of California Press, 2001.

KHOuRY, P. S., Syria and the French Mandate: The Politics of Arab Nationalism, 1920-1945, Princeton, Princeton University Press, 1987.

Khoury, P. S., Urban Notables and Arab Nationalism: The Politics of Damascus, 1860-1920, Cambridge [Cambridgeshire]-Nueva York, Cambridge University Press, 1983.

KHURI-MAKDISI, Ilham, The Eastern Mediterranean and the Making of Global Radicalism, 1860-1914, Berkeley, University of California Press, 2010.

KING, Mary Elizabeth, "Traditional Symbols Confront Modern Repression", Waging Nonviolence. People Powered News and Analysis, 6 de noviembre de 2011. [wagingnonviolence.org/2011/11/ traditional-symbols-confront-modern-repression.]

Lockman, Z., Comrades and Enemies: Arab and Jewish Workers in Palestine, 1906-1948, Berkeley, University of California Press, 1996.

Lockman, Z., Workers and Working Classes in the Middle East: Struggles, Histories, Historiographies, Albany, State University of New York Press, 1994.

Mahmood, Saba, Politics of Piety: The Islamic Revival and the Feminist Subject, Princeton, Princeton University Press, 2005.

Makdisi, U. S., Artillery of Heaven: American Missionaries and the Failed Conversion of the Middle East, Ithaca, Cornell University Press, 2008.

Makdisi, U. S., The Culture of Sectarianism: Community, History, 
and Violence in Nineteenth-century Ottoman Lebanon, Berkeley, University of California Press, 2000.

Meouchy, N. et al., France, Syrie et Liban, 1918-1946: les ambiguïtés et les dynamiques de la relation mandataire, Damas, Institut Français d'Études Arabes de Damas, 2000.

Mohammad, Hani, "Yemeni Women burn Veils in Protest", The Washington Post, 26 de octubre de 2011. [washingtonpost.com/ world/yemeni-women-burn-veils-in-protest/2011/10/26/gIQApPURJM_gallery.html\#photo =1.]

Pastor DE MARIA Y CAMPOS, Camila, "Palestina como espectáculo en la prensa del mabjar mexicano", en Ranaan Rein (ed.), Más allá del Medio Oriente. Las diásporas judía y árabe en América Latina, Granada, Universidad de Granada, 2012.

Pastor de Maria y Campos, Camila, "The Mashreq in Mexico. Patronage, Property and Class in the Postcolonial Global”, tesis de doctorado, Universidad de California, Los Ángeles, 2009.

Provence, Michael, The Great Syrian Revolt and the Rise of Arab Nationalism, Austin, University of Texas Press, 2005.

SAID, Edward W., Orientalism, Nueva York, Pantheon Books, 1978. Silverstein, Paul A., Algeria in France: Transpolitics, Race, and Nation, Bloomington, Indiana University Press, 2004.

Singerman, D., Avenues of Participation: Family, Politics, and Networks in Urban Quarters of Cairo, Princeton, Princeton University Press, 1995.

Singerman, D. y H. Hoodfar, Development, Change, and Gender in Cairo: A View from the Household, Bloomington, Indiana University Press, 1996.

Thompson, Elizabeth, Colonial Citizens: Republican Rights, Paternal Privilege, and Gender in French Syria and Lebanon, Nueva York, Columbia University Press, 2000.

Von RoHr, Mathieu, "Freedoms at Risk. Arab Women Fight to Defend their Rights", Spiegel Online. International, 29 de noviembre de 2011. [spiegel.de/international/world/freedoms-at-risk-arabwomen-fight-to defend-their-rights-a-800447.html.]

Watenpaugh, Keith David, Being Modern in the Middle East: Revolution, Nationalism, Colonialism, and the Arab Middle Class, Princeton, Princeton University Press, 2006. 
